\title{
CINEMA E SOCIABILIDADES: A PROJEÇÃo DA SÉtIMA ARTE NA MATERIALIDADE CONSTRUTIVA
}

\author{
Sabrina Fernandes Melo \\ Universidade Federal de Santa Catarina \\ sabrina.fmelo@gmail.com
}

\section{Resumo}

A arquitetura assume um importante papel no entendimento da cidade se relacionada a outros aspectos da história urbana, uma vez que ela seria uma forma de memória, uma reminiscência capaz de dar testemunho ou de narrar seu tempo. Seguindo esta perspectiva, esse artigo abordará as salas de cinema construídas em Florianópolis no decorrer dos anos de 1930, visando perceber de que maneira esses espaços configuraram tanto o imaginário urbano e social como o aspecto físico e estético da cidade.

\section{Palavras-Chave}

Cinema, arquitetura, Florianópolis

\section{Resumen}

La arquitectura tiene un papel importante en la comprensión de la ciudad cuando se relaciona con otros aspectos de la historia urbana. La arquitectura es una forma de memoria, capaz de dar testimonio sobre su tiempo. Este artículo se ocupará de los cines construidos en Florianópolis durante 1930, con el objetivo de verificar cómo estos espacios desarrollaran el imaginario urbano y social y La parte física y estética de la ciudad.

\section{Palabras-clave:}

Cines, arquitectura, Florianópolis

Uma das possíveis formas de apreensão da história urbana é pela visualidade, por meio de imagens icônicas, que englobam o figurativo pintado, o desenhado, 0 esculpido, o fotografado e o construído (arquitetura). Pois "a materialidade conta uma história, tal como o texto suporta uma imagem, que se constrói visualmente, no pensamento" (PESAVENTO, 2002, p. 23). 
A arquitetura, como imagem-texto passível de interpretação e análise historiográfica, é compreendida no campo da 'montagem', da continuação de outras imagens, precisamente pelo seu caráter inacabado e pela impossibilidade de detenção de sua totalidade. Didi-Huberman trata das especificidades de tempos que podem ser criados em uma obra de arte. Neste caso, a arquitetura atuaria na reconfiguração de diversos presentes temporais. Sendo assim, quando estamos diante da imagem de uma obra arquitetônica, tomada como objeto de análise, estamos diante do tempo, ou 'dos tempos' sobrepostos já que:

A imagem representa, pois, o espaço onde se encontram o agora e o não agora $[\ldots]$. O choque desses tempos genealógicos produz a história, na imagem o ser se desagrega: explode e mostra- mas por muito pouco tempode que é feito. A imagem não é imitação das coisas, mas um intervalo produzido de forma visível, a linha de fratura entre as coisas. (Didi-Huberman (2000) apud NASCIMENTO, 2005, p. 09).

Portanto, "é na tensão entre tempos que está a busca e um possível caminho para pensar criticamente as imagens e/ou as obras de arte trazendo à descrição aspectos paradoxais que nelas apontam" (LINS, 2010, p. 108). Considerando que "aquilo que retorna na imagem é a possibilidade do passado" (ANTELO, 2004, p. 09) nota-se, então, além da sobreposição de tempos, a sobreposição de referências, de signos e de significados em cada obra arquitetônica em análise.

A arquitetura pode ser interpretada como moldura para a vida social da cidade moderna, no sentido de compor o aspecto material da cidade que, ao mesmo tempo, comporta outras inúmeras atribuições de cunho estético, funcional, social, cultural e também de memória. Sobre essa perspectiva de definição da arquitetura Pesavento (2002) afirmou que:

A memória pode ser oral, escrita ou de pedra. As lembranças podem chegar até o tempo do presente com vozes, com narrativas que deixam o testemunho escrito de uma vivência e de uma percepção, ou como materialidade em um espaço construído, a atestar, com eloquência objetiva, a visualidade do passado. A rigor, tudo, na cidade, pode ser convertido em fonte, em documento para o historiador da urbs, para que ele possa construir sua narrativa (PESAVENTO, 2002, p. 30). 
Partindo deste pressuposto, Pesavento (2002b), considera que a arquitetura pode ser percebida como resultado material de um pensamento ao atuar na fixação ou registro de informações no espaço urbano. Nesse sentido, e tomando como referência parte da arquitetura de Florianópolis a ser discutida neste artigo, estas imagens urbanas são fontes valorosas para a composição de uma moldura citadina construída durante a primeira metade do século XX.

As salas de cinema modificaram a paisagem edificada de Florianópolis, que gradativamente se desvencilhava das construções com traçado colonial e neocolonial. Esses novos espaços ganharam um público cativo que prestigiava o que sua arquitetura protegia: as películas, novidade tecnológica tão ansiosamente aguardada. Além disso, esse mesmo público podia desfrutar dos serviços oferecidos por esses espaços e pelos estabelecimentos que ali circundavam, como bares, cafés e lojas. É possível que frequentadores dessas salas se deslocassem de bairros mais distantes para vislumbrarem lançamentos de filmes e para transitarem pelos novos espaços do centro que se modernizava.

Os cinemas ${ }^{1}$, um dos maiores ícones da modernidade, atuaram como agitador cultural e promotor de sociabilidades de Florianópolis - assim como em todas as cidades do Brasil nas quais havia cinema, até a chegada do shopping center -, impulsionando a circulação de pessoas, ideias e referências estéticas relacionadas à arquitetura (cenografia/construção que abarcava o cinema) e a moda (figurino/hábitos), e contribuindo ainda mais para o já movimentado espaço central da cidade. Tal movimento acontecia porque boa parte do divertimento e lazer daquele período se concentrava no entorno da Praça XV de Novembro.

Os serviços e as instalações dos cinemas, como a bonboniére, bar parisiense e galeria de cristal, eram apresentados nos anúncios de jornais de forma democrática. Ou seja, era enfatizado o discurso de que o acesso da população a esse local seria possível. Não havia nos anúncios nada que indicasse as impossibilidades de ocupação desses espaços por pessoas residentes em áreas periféricas, por exemplo.

Um cinema que enfatizava esse caráter democrático do espaço, a começar pelo próprio nome e pelos preços populares das sessões, era o antigo Centro Popular, posteriormente denominado cine Roxy, construído em 1930 à Rua Padre Miguelinho,

\footnotetext{
${ }^{1}$ A chegada do cinema em Santa Catarina aconteceu por volta de 1900, época em que se fizeram as primeiras exibições com cinematógrafos ambulantes, poucos anos depois da chegada da arte no Brasil. Esses exibidores itinerantes eram viajantes que saíam de cidade em cidade, alugando salões ou teatros e mostrando a mais nova e impressionante maravilha da tecnologia, muitas vezes inserindo também outros números nas sessões. Em Florianópolis não aconteceu como em São Paulo, Rio de Janeiro e Curitiba, onde após longos períodos, apareciam vários cinematógrafos ao mesmo tempo. Na ilha, fez sucesso o Pavilhão Recreativo, um palco de variedades que funcionava sob uma lona de circo, empreendido pelo imigrante italiano José Julianelli que, em 1909, mandou vir de Paris um cinematógrafo para compor mais uma atração no pavilhão (MUNARIM, 2009, p. 81).
} 
ao lado da Igreja Matriz. Ele ocupava o segundo piso do edifício. Já na parte térrea havia lojas e cafés. Ainda hoje há estabelecimentos comerciais, entretanto, a parte superior se encontra fechada para restauração e reformas.

A arquitetura do Roxy define-se como eclética, todavia com algumas especificidades que o distanciam daquele ecletismo praticado no início do século XX, como já visto no capítulo anterior. Em sua fachada há pequenos ornamentos com características geométricas em alto e baixo relevo ${ }^{2}$, insinuando pilastras que remetem ao neoclássico, elemento recorrente em edifícios ecléticos.

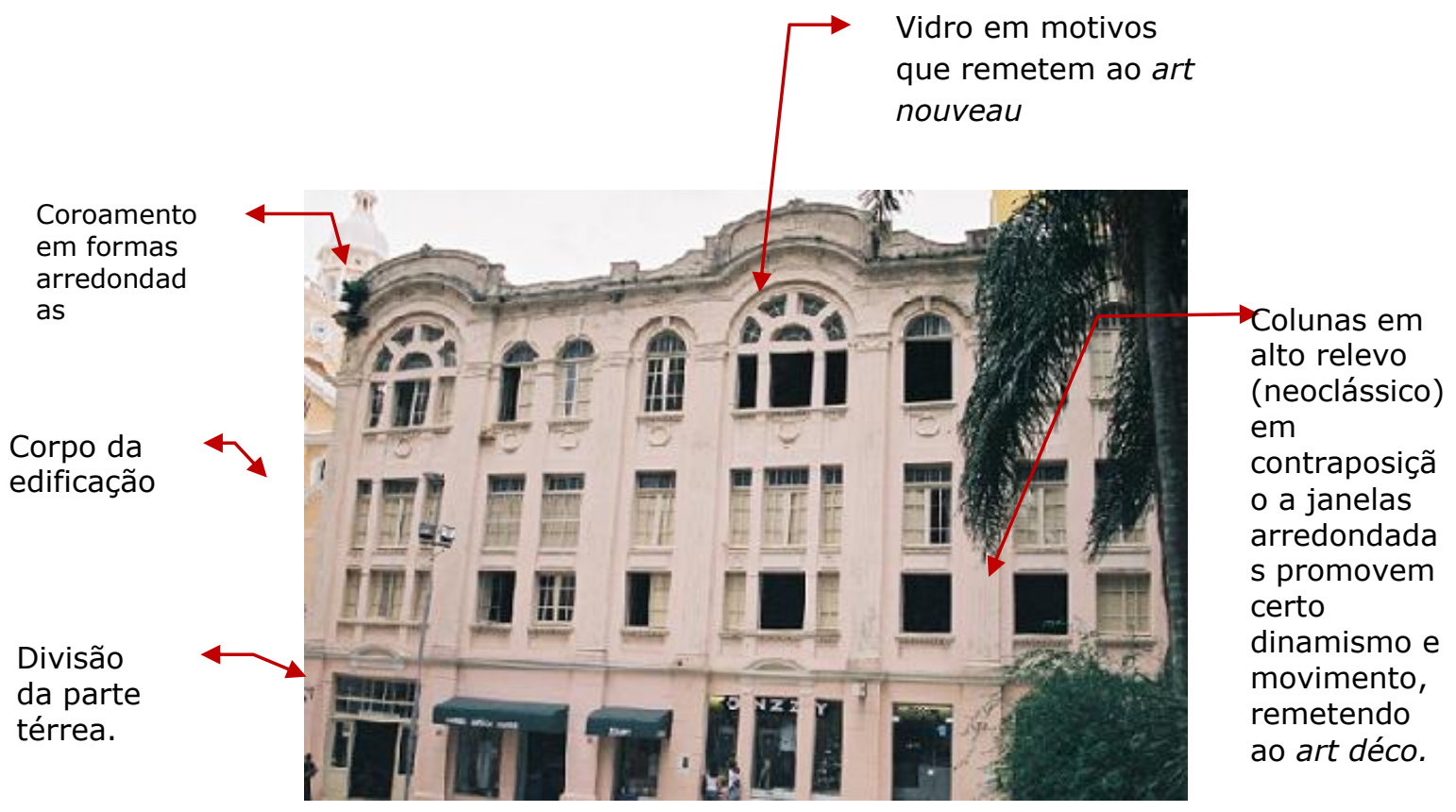

Figura 01: Frente do Cine Roxy. Parte da Catedral aparece ao fundo.

Foto: Sabrina Fernandes Melo, 2011.

As janelas possuidoras de arcos plenos se encontram na parte superior, contrapondo-se às inferiores com ausência de curva. Nas janelas superiores, os detalhes dos vidros são ornamentados, característica que para Teixeira (2009) são influenciadas pelo estilo art nouveau. A edificação está dividida em três partes: o térreo, onde estão as lojas, o corpo da edificação onde há as janelas quadradas e arredondadas e o coroamento na parte superior, que evita a visibilidade do telhado e proporciona maior verticalidade.

Os elementos do art nouveau, que Teixeira (2009) afirmou existir, encontramse na ornamentação em vidro das janelas superiores, nos arcos das janelas arredondadas e nos ornatos da fachada. A coluna em alto relevo - signo do estilo

\footnotetext{
${ }^{2}$ A diferenciação principal entre estruturas de alto e baixo relevo não está associada somente às características volumétricas da peça. $O$ baixo relevo define-se quando suas formas não ultrapassam a visão frontal, já no alto relevo existe uma tridimensionalidade mais evidente.
} 
neoclássico, a nítida divisão da edificação em três partes (base, corpo e coamento) e incorporação de elementos do art nouveu dentre outras, configuram esta edificação como eclética. Todavia, há que se considerar que mesmo possuindo tendências ecléticas, essas tendem a um direcionamento mais racional em suas formas, pois a fachada do edifício não possui muitos ornamentos.

São discretos os poucos ornamentos concentrados abaixo das janelas e do coroamento da edificação, características de um direcionamento racional manifestas na linearidade das formas e no dinamismo das curvas. Consequentemente desencadeia a alternância entre linearidade e movimento, características típicas do art déco.

O anúncio de (fig.02) indica que o evento construção em si, eram arquitetônico quanto pelo questões da estética e da apresentado como um referente ao social ele é "ricos e pobres terão as parisiense, um mobiliário crystal fulgurante". inauguração do cine Rex

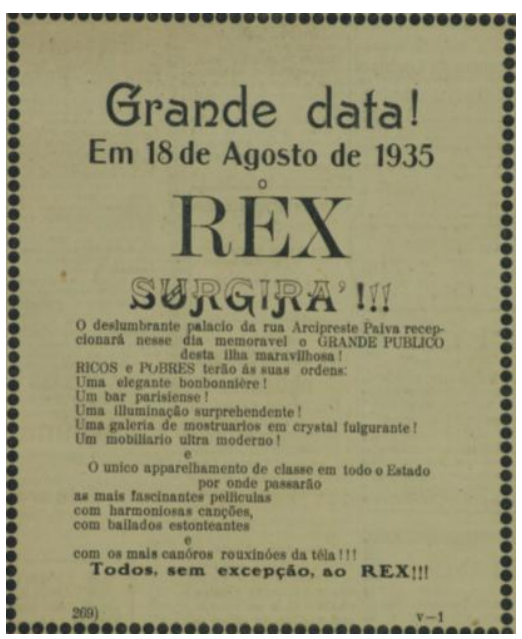
abrigado pela construção e a vistos, tanto pelo viés social. No que se refere a arquitetura, ele é "deslumbrante palácio", aberto para todos, onde suas ordens 0 bar ultramoderno, a galeria de

Figura 02: Anúncio ${ }^{3}$ de inauguração do Cine Rex .

Fonte: O ESTADO, 05 jul, 1935, p. 04. Apud TEIXEIRA, 2009, p. 234.

\footnotetext{
${ }^{3}$ No anúncio lê-se: "O deslumbrante palácio da rua Arcipestre Paiva recepcionará neste dia memorável o Grande Público está ilha maravilhosa! Ricos e Pobres terão às suas ordens: uma elegante bombonniére! Um bar parisiense! Uma iluminação surprehendente! Uma galeria de mostruários de crystal fulgurante! Um mobiliário ultra moderno! e o único aparelhamento de classe em todo o Estado, por onde passarão as mais fascinantes películas, com harmoniosas canções, com bailados estonteantes e com os cánoros rouxinóis da tela!Todos, sem excepção, ao CINE REX!
} 
Além de contar com todas essas características, o cinema possuía o "único aparelhamento de classe de todo o estado". "Todos sem, exceção, ao cine REX". Todos os moradores, sem exceção, estariam convidados e teriam possibilidades reais - segundo o anúncio, de se integrarem a esse acontecimento que ultrapassava a sala de projeções. Quanto ao desenho externo do Ritz, sua fachada é composta por uma porta principal com marquise, elemento que se tornou uma das características "marcantes de identidade da arquitetura moderna brasileira" (GHIRARDELLO, 2003, p. 02).

A marquise certamente tinha a função de proteger a entrada da edificação, controlando a incidência solar, a chuva, além de, eventualmente, ter servido de abrigo para pedestres, contribuindo, em muitos casos, com a elaboração de um projeto arquitetônico harmônico visualmente usado, na maioria dos casos, em prédios públicos e comerciais ${ }^{4}$. Por consequência, sua adoção atestaria o uso de novas técnicas e materiais construtivos modernos, como o concreto armado e aço ${ }^{5}$. Pelas imagens (figuras. 03 e 04) verifica-se que a marquise foi expandida para toda a extensão da construção.

Essa expansão pode ter sido ocasionada por diversos fatores. Primeiro para proporcionar mais proteção e também maior imponência ao exterior do edifício. Relacionada à funcionalidade a marquise ofereceria maior comodidade aos frequentadores do cinema ao protegê-los das intempéries da natureza durante a espera na fila pela abertura das portas. Talvez a extensão da marquise por todo o prédio tenha sido efetivada por causa do aumento progressivo do público.

Na entrada da Rua Arcipestre Paiva, o Cine Ritz contava com afastamentos laterais, ou seja, a sistemática adoção do concreto armado e dos conceitos da arquitetura modernista implicou na construção de plantas elevadas, afastadas da calçada e com maiores aberturas laterais. Visava-se à maior circulação de ar e ao aumento da privacidade. Decorre daí a modificação dos lotes coloniais, passando a existir uma distância mínima necessária entre a calçada e a porta de entrada da edificação. Entretanto, em sua saída, na Rua Padre Miguelinho, esses afastamentos não foram efetivados, fazendo com que os Cines Ritz e Roxy ficassem geminados.

Contudo, nem a opulência dos prédios, nem os anúncios 'democráticos' e nem os detalhes afrancesados dos ambientes internos, impediram os cines Roxy e Ritz de

\footnotetext{
${ }^{4}$ Atualmente existe uma discussão sobre o uso das marquises, que não são elementos indispensáveis às construções. Em alguns estados como o Rio de Janeiro, a utilização de marquises foi proibida devido ao elevado número de desabamentos e acidentes provocados. O desabamento de marquises é associado à ausência de pilares de sustentação para estas estruturas.

${ }^{5}$ Concreto armado é um material de construção resultante da união do concreto simples e de barras de aço, envolvidas pelo concreto, com perfeita aderência entre os dois materiais, de tal maneira que resistam ambos solidariamente aos esforços a que forem submetidos.
} 
cometerem certos 'deslizes', pois mesmo possuindo algumas características de um cine palácio, eles ficaram destituídos de elementos funcionais relativos a esse tipo de construção. No Roxy não havia, por exemplo, ausência de bilheteria separada, ou seja, voltada para o lado externo da edificação, já a ausência de suportes para a divulgação dos cartazes dos filmes não existia em ambos os cinemas. Como se pode observar na imagem do cine Roxy, estes cartazes eram expostos no chão afixados improvisadamente nas paredes. Na tentativa de modificar essa situação negativa, estética e visualmente, em 1929, foi instaurado um imposto sobre a publicidade.

Qualquer cartaz, letreiro, anúncios em prédios, muros, trapiches, telhados, enfim, qualquer anúncio que estivesse em qualquer local visível ao público estaria sujeito a diferentes valores de cobrança. Nos cinemas e teatros seria cobrado o valor mensal de cinco mil réis, para letreiros que ocupassem o espaço de até um metro na parede, já os anúncios móveis fixados em cavalete valiam quinze mil réis os que estivessem em língua estrangeira, vinte mil réis.

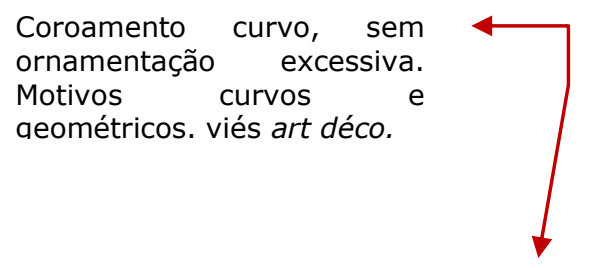




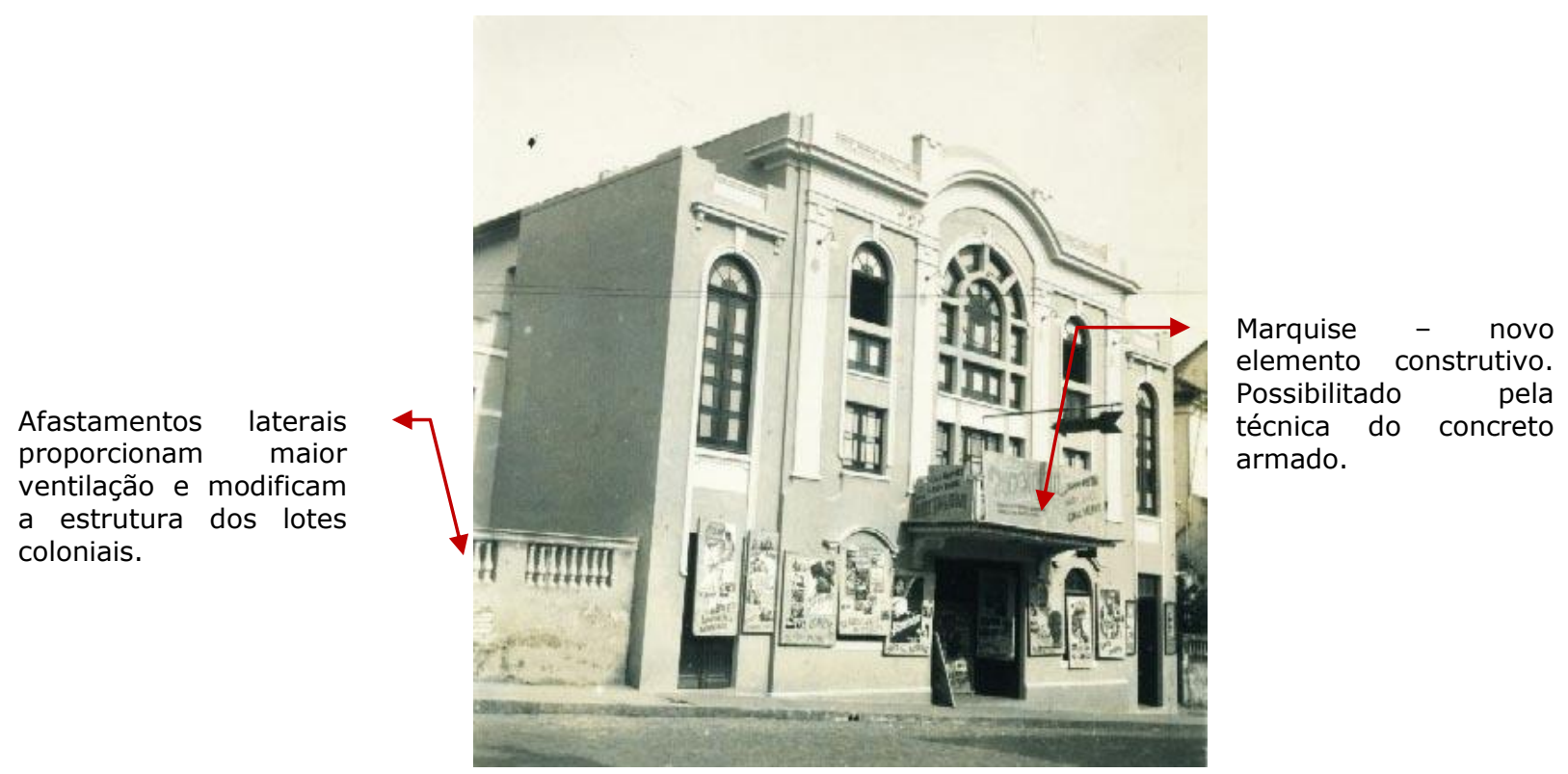

Figura 03: Cine Ritz. (s/d.). Presença de inúmeros cartazes para promoção/propaganda de filmes.

Fonte: Acervo da Casa da Memória

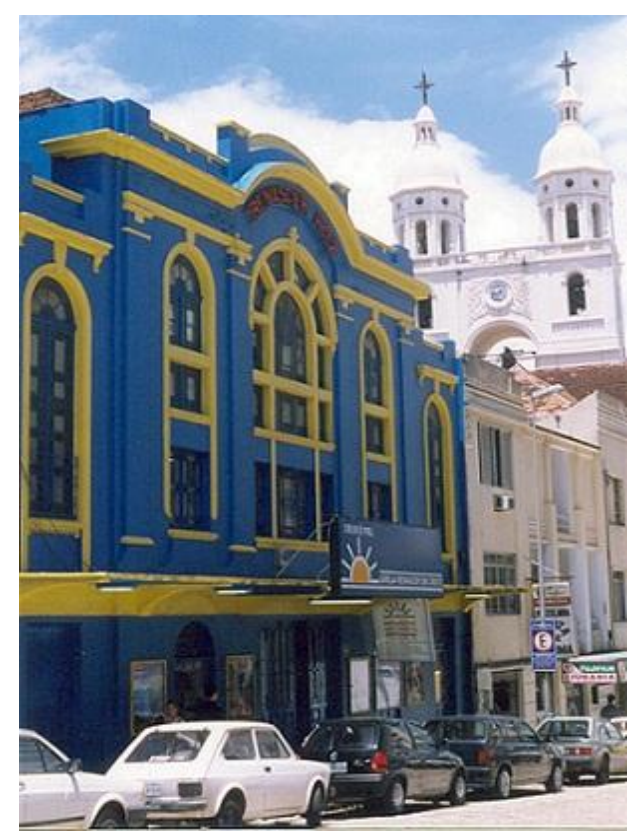

Figura 04: Cine Ritz. (s/d).

Fonte: Acervo da Casa da Memória.

Se nos anos iniciais do século $\mathrm{XX}$, o cinema por si só já era um reconhecido ícone da modernidade, o cine Ritz e o Roxy não apenas proporcionaram a população, mas também à Florianópolis, o acesso à modernidade cultural ao inaugurarem na cidade a sétima arte. Embora salas de cinema, como os Cines Ritz e Roxy, buscassem expressar a modernidade na materialidade de suas construções algumas salas, como foi o Cine Variedades, adaptaram-se a espaços já existentes. 
Anexado ao lado do antigo casarão do Teatro Álvaro de Carvalho (TAC), fundado em 1857, o Cine Variedades, um clássico exemplar da arquitetura colonial, após reformas, como ocorreu na maioria dos edifícios apresentados até o momento, passou a possuir linhas ecléticas. Ele, embora posteriormente tenha sido substituído, em primeiro lugar pelo cine Odeon, e depois pelo Royal, ganhou o status de inaugurador, na cidade, do cinematógrafo Lumiére veículo de acesso às imagens em movimento sobre uma tela branca.

\subsection{CINE-NOTA}

Somente no ano de 1930 foram inauguradas duas novas salas de cinema em Florianópolis, o Cine Glória e o Cine Ideal. O primeiro, dirigido pelos Srs. Moura \& Irmãos, situava-se no distrito do Saco dos Limões, um pouco mais afastado do perímetro central, estreando O Príncipe Fazil, dividido em oito longos atos. Em 1932, foi inaugurado um novo Cine Glória que seria "incontestavelmente o melhor salão de projeções desta capital" (O ESTADO, 1932, p. 05), tendo como filme de estreia $A$ Deusa Africana ${ }^{6}$. Já o Cine Ideal foi instalado na sede em que funcionava o antigo Banco Sul do Brasil à Rua Conselheiro Mafra. Redatores do jornal fizeram uma visita ao local em que seria inaugurado o Cine e afirmaram que estava "optimamente decorado em stylo moderno" (O ESTADO, 1930, p. 06).

A chegada desse novo espaço de divertimento parece ter agradado não apenas aos espectadores que posteriormente puderam assistir a diversos filmes, mas contou com a aprovação antecipada dos colunistas, que consideraram esta empreitada como "um grande melhoramento este que o senhor Abrahão Buatin vai introduzir em nossa capital que não se peja de possuir uma só casa de diversões" ( $O$ ESTADO, 1930, p. 02). Nesta mesma notícia, o pesar era evidente ao assumir que a capital do estado possuía poucos locais de lazer quando comparada a cidades menores.

As salas de cinema foram alvos constantes das crônicas jornalísticas. A discussão sobre a limitação dos espaços de lazer às salas de cinema proporcionou uma ampla discussão sobre a função destes espaços e sobre as práticas adotadas no interior deles. Em uma coluna semanal com o sugestivo nome de Maus Costumes ( $O$ ESTADO, 1931, p. 06) colaboradores anônimos do jornal O Estado, escreveram sobre comportamentos considerados inconvenientes para a vida na cidade. Estes deveriam

\footnotetext{
${ }^{6}$ Em 1960 o Cine Glória se estabeleceu no Estreito, onde permaneceu até a demolição do prédio que ocupava na década de 1980 . O prédio que ocupava foi demolido.
} 
ser substituídos por outras condutas, especificadas na maioria dos textos desta coluna semanal.

Reclamações sobre a falta de opção de diversão foi também uma constante nas crônicas. Na mesma medida em que cronistas se dedicavam a escrever sobre os pontos positivos que o evento cinematográfico trouxera para a capital, outros afirmavam que este tipo de diversão sofria de uma monotonia ocasionada pela rotina.

O cronista Braz Cubano protestava contra a lenta dinâmica urbana da cidade, que para ele ainda sofria da "velha saudade lusíada do desterrado" (CUBANO, 1930, p. 06) ao considerar que a maioria dos habitantes preferia o silêncio monótono e contemplativo dos bancos das praças do que apreciar uma boa música tocada por uma das quatro bandas existentes na cidade, duas civis e duas militares. Para Braz, essa situação poderia ser mudada caso houvesse vontade política de trazer para a capital mais opções de lazer e diversão.

O cronista M possuía opinião idêntica a de Braz Cubano sobre as opções de lazer da cidade, que diminuíam consideravelmente nos dias de domingo. Para M os domingos em Florianópolis eram "uma coisa insulsa e insuportável" (M, 1931, p. 06), pois havia apenas duas opções de entretenimento neste dia da semana, o Corso insípido no Oliveira Belo e os cinemas, alternando "corso e cinema em um domingo e cinema e corso em outro domingo, guisa de menu de restaurante do interior, com ovos e linguiça no almoço e linguiça e ovos ao jantar, acaba por deixar um cidadão ilustre ou não, completamente bestificado"(M, 1931, p. 06) e completava:

Leva-se uma semana inteira de lutas. Seis dias a fio ali no duro, nessa vidinha trabalhosa e agitada, para afinal, no domingo dia de recreio e descanso mumificar-se a gente num banco de casa de cinema, para ouvir cânticos exóticos, falar em inglês morrendo de arrependimento pela falta dos três mil réis. E quando não este supliciar-se o cidadão no escuro do cinema, onde as estrelas americanas tem um brilho fugidio, vai o pobre mortal rodar, rodar, idiotamente, aparvalhadamente em volta dos canteiros dos jardins (M, 1931, p. 06).

Durante os anos de 1930, a diminuição da presença do público nas peças teatrais e o aumento significativo da construção de novas salas de cinema foram evidentes. O cinema estava em alta como um legítimo acontecimento urbano e estava, de fato, incorporado na sociedade. O hábito que na belle époque era ainda incipiente passa a ser um habitus mediador que auxiliou a balizar uma 
homogeneidade nos gostos e nas preferências de grupos e indivíduos o que, de certa maneira, contribuiu para a construção novas identidades sociais.

Construções mentais, visuais e perceptivas do tempo/espaço, foram profundamente alteradas com o advento do cinema e seus desdobramentos, como a perspectiva fotográfica, modificando a maneira de ler e interpretar a realidade. Essas mudanças no comportamento e no gosto em parte dos habitantes de Florianópolis produziu um efeito direto na oferta e demanda de novas formas de divertimento. As salas de cinema tinham um público cativo que prestigiava as películas e desfrutavam dos serviços oferecidos por estes espaços e pelo comércio que ali circundavam, como bares, cafés e lojas.

Metrópolis do diretor Fritz Lang, um dos filmes mais aclamados dos anos trinta foi projetado no Cine Variedades e ganhou destaque nas colunas de jornais (figura 05). A propaganda para esse filme foi diferenciada, pois ocupava meia página do jornal, contava com imagens de cenas do filme e com a presença de diferentes fontes de letras que chamavam atenção para o anúncio. O filme faz alusão à máquina e a uma metrópole futurista, com presença de automóveis, trens e veículos voadores. 0 cenário, de alto custo para os padrões da época, era em art déco, estilo arquitetônico de diversas construções da cidade.

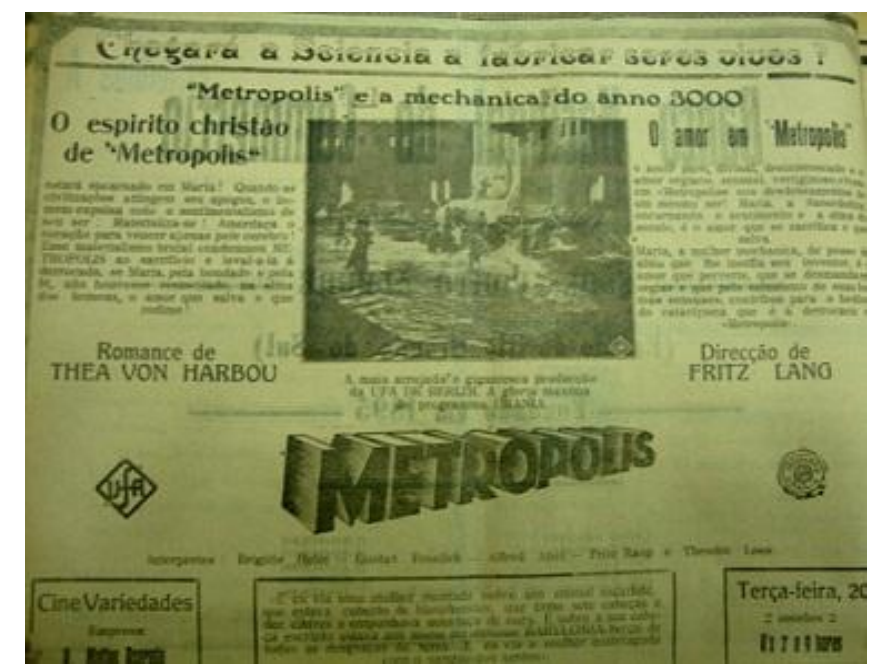

Figura 05: Anúncio Publicitário do filme Metrópolis.

Fonte: O ESTADO, Florianópolis, 13de maio, 1930, p.08.

Foto: Sabrina Fernandes Melo, 2012.

Metrópolis retrata uma cidade do século XXI, no ano de 2026, em que habitavam operários, considerados as mãos da cidade, e os mestres, que seriam as cabeças. Os operários viviam na parte subterrânea e os mestres na superfície. Em diversas cenas são retratadas as disparidades sociais existentes entre estas duas 
classes com base nas diferenças das jornadas de trabalho, de postura corporal que anunciavam trabalhadores tristes, cabisbaixos, maltrapilhos e com aspecto doente e em contrapartida, os habitantes da superfície são sadios, alegres e atléticos.

As classes sociais são diferenciadas também pela arquitetura dessas duas cidades que compõem Metrópolis. A superfície onde habitam os mestres ou a classe dominante é composta por gigantescos e imponentes edifícios, modernos e suntuosos ligados por ruas estreitas onde circulam automóveis e sobrevoam aviões. Já na parte subterrânea da cidade, as construções são padronizadas e lembram as cidadesdormitório, com função quase exclusiva de descanso para os trabalhadores durante as breves horas de folga. Metrópolis manifesta o medo e a insegurança perante às cidades industriais.

O espaço urbano fílmico simulado em Metrópolis e, em outros filmes, é imprescindível para a análise da cidade imaginária criada pelo cinema. Ele desempenha o papel de instrumento revelador de uma nova realidade: a cidade das aparências e da simulação de espaços. O cinema como porta-voz do desejo por uma representação e vivência simbólicas revela a sobreposição entre realidade e imaginário gerado pelo culto imagético dos cidadãos.

A cidade real e imaginada não são apenas produtos de imagens fílmicas, mas também de discursos, pois "sempre existe uma cidade ideal dentro ou sob a cidade real, distinta desta como o mundo do pensamento é do mundo dos fatos" (ARGAN, 2005, p. 73). Durante as primeiras décadas do século XX, Florianópolis possuía, de forma bem demarcada, duas cidades: a ideal, conceituada com o discurso médico, higienista, sanitarista, modernizador e a 'real', onde operavam práticas não condizentes com o ideário balizado por tais correntes. Além da alteração de posturas individuais e coletivas, como hábitos de higiene, boas maneiras e condutas morais, foram modificadas também as formas de construir, de reformar e de praticar/ocupar o espaço.

A cidade ideal, representada aqui por um filme de ficção científica, pode ser também construída e imaginada pelas crônicas futuristas - aquelas que imaginam a situação ideal da cidade pautada nos problemas do presente, visto que "a crônica futurista é tão cifrada ou inventiva na sua configuração quanto os filmes de ficção científica que dão a ver como em um tempo dado se pensa o futuro" (PESAVENTO, 2004, p. 74).

Assim como em Metrópolis, Florianópolis possuía uma nítida diferença estética e social entre a cidade dos ' trabalhadores' e a dos 'mestres'. Os bairros Tronqueira, Figueira e Toca eram verdadeiros nichos de insalubridade e de comportamentos 
impróprios como "o dos menores vadios ou das mulheres de vida decaída" (ARAUJO, 1989 , p. 17). Nestas regiões viviam lavadeiras, soldados, negros libertos e pescadores que habitavam casebres e cortiços constantemente associados a focos de doenças e epidemias. Na tentativa de modificar essa realidade foram aplicadas medidas de saúde, como a abertura de postos e hospitais para atender a população e medidas que visavam regulamentar as construções.

Conclui-se que o cinema foi um dos mais importantes acontecimentos urbanos da cidade na primeira metade do século $X X$. Um evento social coletivo que desempenhou a função de mediador e propulsor de novos hábitos, produtos e preferências. Ele instaurou inovações tecnológicas como a perspectiva fotográfica e a possibilidade de vislumbrar imagens em movimento. Seguramente, tais inovações alteraram as percepções dos indivíduos em relação ao tempo e ao espaço.

Seguindo a perspectiva apresentada por Setton (2002), emerge deste evento um espaço para se pensar a constituição da identidade social do indivíduo moderno. 0 cinema influenciou paradigmas para a construção das paisagens urbanas, visto que os espaços fílmicos e seus cenários dialogavam diretamente com as cidades. Tal discussão foi fomentada pelo filme Metropolis, cujo cenário é em art déco. Este Filme foi projetado em Florianópolis, em meados de 1930, período em que o art déco se transportava das telas diretamente para a renovação estilística das casas, do comércio e para os novos edifícios.

\section{Fontes}

O ESTADO. Florianópolis, 24 fev, 1930, p. 02.

. Florianópolis, 08 jul, 1930, p. 06.

. Florianópolis, 14 mar, 1932, p. 05.

CUBANO, Braz. Cinema ao ar livre. O Estado, Florianópolis, 05 abril, 1930, p. 06.

M. Os domingos em Florianópolis. O Estado, Florianópolis, 03 ago, 1931, p. 06.

Maus costumes. O Estado. Florianópolis, 06 ago, 1931, p. 06.

\section{Referências}

ANTELO, Raúl. Potências da Imagem. Chapecó: Argos, 2004.

ARAUJO, Hermetes Reis de. A invenção do litoral: reformas urbanas e reajustamento social em Florianópolis na Primeira Republica. São Paulo, 1989. 216 p. Dissertação (Mestrado) Pontifícia Universidade Católica de São Paulo, 1989.

ARGAN, Giulio Carlo. História da arte como história da cidade. São Paulo: Martins Fontes, 2005. 
GHIRARDELLO, Nelson. Marquises Modernas. In: Seminário DoCoMOMO- Brasil, 2003, São Carlos. DOCOMOMO - Anais 5 Seminário DOCOMOMO- Brasil, Arquitetura e Urbanismo Modernos: Projeto e Preservação. São Carlos: Arquivo de Computador/ Comissão organizadora: SAP/ EESC/ USP, 2003.

LINS, Jacqueline Wildi. Arte, Imagem e Memória. In: FLORES, Maria Bernardete Ramos Flores; VILELA, Ana Lucia. (Org.). Encantos da imagem: estâncias para a prática historiográfica entre história e arte. Florianópolis: Letras Contemporâneas Oficina Editorial, 2010, p. 103-112.

NASCIMENTO, Roberta Andrade. Charles Baudelaire e a arte da memória. Alea: Estudos Neolatinos, Rio de Janeiro, v.7, jan./jun.2005. Disponível em: <http://www.scielo.com.br>. Acesso em 29 nov. 2012.

PESAVENTO, Sandra Jatahy. Memória, história e cidade: lugares no tempo, momentos no espaço. In: ArtCultura, Revista do Nehac, Universidade Federal de Uberlândia, v. 4, n. 4, p. 23-35, 2002b.

. Crônica: Fronteiras da Narrativa histórica. In: História Unisinos vol. 08, no 10. p. 62-80, 2004. Disponível em: <http://pt.scribd.com/doc/52215228/PesaventoCronica-e-narrativa-historica>. Acesso em 08 nov. 2012.

SETTON, Maria da Graça Jacintho. A teoria do habitus em Pierre Bourdieu: uma leitura contemporânea. In: Revista Brasileira de Educação, no 20, mai/jun/jul/ago 2002. São Paulo: USP/Faculdade de Educação.

TEIXEIRA, Luiz Eduardo Fontoura. Arquitetura e cidade: a modernidade (possível) em Florianópolis, Santa Catarina-1930-1960. 2009, 337 p. Tese (Doutorado). Escola de Engenharia de São Carlos da Universidade de São Paulo, 2009. 